University of Nebraska - Lincoln

DigitalCommons@University of Nebraska - Lincoln

Winter 12-2011

\title{
Mapping Injustice: The World is Witness, Place-Framing, and the Politics of Viewing on Google Earth
}

Joshua P. Ewalt

University of Nebraska - Lincoln, joshua.ewalt3@huskers.unl.edu

Follow this and additional works at: https://digitalcommons.unl.edu/commstudiespapers

Part of the Communication Technology and New Media Commons, Critical and Cultural Studies

Commons, Human Geography Commons, Mass Communication Commons, Organizational

Communication Commons, and the Rhetoric Commons

Ewalt, Joshua P., "Mapping Injustice: The World is Witness, Place-Framing, and the Politics of Viewing on Google Earth" (2011). Papers in Communication Studies. 36.

https://digitalcommons.unl.edu/commstudiespapers/36

This Article is brought to you for free and open access by the Communication Studies, Department of at DigitalCommons@University of Nebraska - Lincoln. It has been accepted for inclusion in Papers in Communication Studies by an authorized administrator of DigitalCommons@University of Nebraska - Lincoln. 


\title{
Mapping Injustice:The World is Witness, Place-Framing, and the Politics of Viewing on Google Earth
}

\author{
Joshua P. Ewalt \\ Department of Communication Studies, University of Nebraska-Lincoln, Lincoln, NE 68588-0329, \\ USA; email joshua.ewalt3@huskers.unl.edu
}

\begin{abstract}
Working from assumptions that inequality is often spatially informed, a set of interactive cartographies has recently proliferated on Google Earth. In this essay, I analyze one of these interactive cartographies: the World is Witness, produced by the United States Holocaust Memorial Museum (USHMM). I read the map as an organizational rhetoric that frames place as "embedded injustice." I also argue that thorough analysis of the framing of local place on Google Earth must inherently question whether the map can create a disruption in the viewing subject. While the map presents vital information on excruciatingly despicable acts of injustice, and the USHMM should be praised for its actions, it reinforces and is reinforced by the politics of viewing on Google Earth.
\end{abstract}

We live in a map-immersed world. A plethora of maps surround us at any given moment. Road maps help us find a new school or restaurant, a concert venue, or an auto shop. Weather maps inform us about climate and storm patterns across geographies, and city maps give insight into crime patterns. Around election time, political maps construct "blue states" and "red states." Tourist maps rhetorically construct certain spaces as exotic and unique and help us situate our bodies within these visitor-friendly spaces, meanwhile facilitating a colonialist construction of the identities of those hosts who live in the spaces (Del Casino \& Hanna, 2000). With each of these cases, it is clear that the maps encountered in our everyday lives are used to both navigate and politically construct the spaces and places within which human beings reside.

Recently, certain maps have been used to organize geographies around themes of injustice, oppression, or political resistance. These maps, often called 
countermaps or participatory cartography (Bauer, 2009; Hodgson \& Schroeder, 2002; Wainwright \& Bryan, 2009), are used by a collection of social movement organizations, nongovernmental organizations, and even some government entities to resist social, economic, or global oppression. Considered a part of the countermapping movement (i.e., Hodgson \& Schroeder, 2002; Wainwright \& Bryan, 2009), these organizations use a multitude of cartographies - from physical maps to simulations of built environments on virtual worlds - in order to organize collective action around spaces of injustice. Keith and Pile (1993a), following Jameson (1991), get to the heart of the countermapping movement when they state:

It is ... meant to allow people to become aware of their own position in the world, and to give people the resources to resist and make their own history. It is the logic of capital itself which produces an uneven development of space. These spaces need to be "mapped," so that they can be used by oppositional culture and new social movements against the interests of capital as sites of resistance. (p. 3)

In a global world, where spaces of oppression are increasingly difficult to locate (Harvey, 1993; Shome \& Hegde, 2002), maps help us locate and articulate geopolitics of resistance.

Contemporary examples of countermapping abound: Maya and Mayangna communities in Nicaragua and Belize, for instance, have used maps to facilitate reasoning and construct evidence in human rights lawsuits (Wainwright \& Bryan, 2009). The Pluto Project subversively mapped post-Cold War landscapes in order to illustrate unchecked state control and to "create awareness about injustice in the power of states and to promote peace" (Barney, 2009, p. 418). Indigenous groups in Venezuela have utilized cartographies to construct counterhegemonic political borders to regain control of their natural resources (Sletto, 2009). All of these examples illustrate how different places are constructed and networked by focusing on one item that can counteract dominant rationalities.

One of the most prominent sites of countermapping is Google Earth. Facilitated by the financial and educational resources of Google EarthOutreach - the division of Google Earth concerned with utilizing its software for socially conscious purposes-a number of organizations have begun mapping organizational initiatives and social injustices on a virtual image of the Earth. For instance, the United States Holocaust Memorial Museum (2009) states, "[USHMM] uses tools such as Google Earth and animated maps to enable citizens to understand Holocaust history and bear witness to current threats of genocide across the globe." The World Wildlife Fund (WWF) highlights the importance of creating maps that allow Google Earth users to view the mission, goals, and identity of its organization:

With more than 45 years of on-the-ground experience, WWF is excited that people everywhere will have the opportunity to zoom in on a sample of our projects ... users of Google Earth will be able to learn about the geographical location of selected WWF projects, read a description of each and be directed to WWF's global website." (Malone, 2007) 
Using the global media resources offered by Google Earth Outreach, organizations ranging from Greenpeace and the WWF to the USHMM are able to associate imagery, narratives, and videos with geographies to map spaces of oppression and resistance. In this sense, countermaps on Google Earth are inherently organizational rhetorics of social change wherein geographies are mapped and produced to illustrate spatial injustice. ${ }^{1}$

Despite recent work on Google Earth, countermapping, and the production of geographies as the loci of social change, there has yet to be a systematic examination of the intersection of these three subjects. Namely, work is needed that addresses how Google Earth cartographies create, or frame, place in order to motivate users of the medium. In addition, while past essays have expressed the nature of ideological viewing inherent on Google Earth (e.g., Stahl, 2010), there has yet to be a full examination of how the construction of local place either reinforces or introduces a critical break in the user's relationship to spatial satellite imagery. An examination that considers the process of interactive mapping on Google Earth as a rhetoric that makes and frames place for the purposes of motivating action in users who are already constituted by the constraints of political viewing is needed.

That is precisely my goal. In this essay, I examine one countermap on Google Earth: The World is Witness map produced by the USHMM. I argue the process of interactively mapping the virtual earth is an act of place-framing, a process by which space is transformed to place so as to motivate action on the part of those constituencies potentially sympathetic to the organization's goals. Specifically, I argue that the USHMM frames local places in Africa using an "embedded injustice" place-frame. This involves stating that while the World is Witness map provides important information on despicable acts of human violence, the framing of place as "embedded injustice" naturalizes the African continent, primarily Rwanda, Darfur, and the Democratic Republic of Congo, as spaces of destructive violence, offers solutions that praise global entrance into place, and constructs a motivated subject characterized by a distanced empathy. Because of this construction of local place, and the spatial positioning of the Google Earth user that accompanies it, the map may unintentionally reinforce problematic geocolonial subjectivity, which reinforces and is reinforced by the politics of viewing spatial satellite imagery on Google Earth.

I begin by establishing the academic grounds for study. This requires establishing the relationship between place and organizational rhetorics of social change. Part of this involves explaining the difference between space and place, and explaining the construction of place as a rhetorical process. I then proceed to outline one of the more useful approaches to the rhetorical construction of place as a feature of social change, and the explanation that most informs my interpretation of interactive maps on Google Earth: Place-framing (Martin, 2003). Before introducing my analysis of the place-framing of the World is Witness map, I support my proposition that one heuristic approach to analyzing countermaps on Google Earth is to focus on how they create place in such a way as to disrupt the politics of viewing satellite imagery. The implications of this analysis should ex- 
tend to work on place, countermapping, collective action, and the strategic use of Google Earth for advocating social change.

\section{The Rhetorical Construction of Place and Social Change}

\section{Space and the making of place}

As countermaps on Google Earth are rhetorics produced by social change organizations in order to provide a perspective on geographies of injustice, it is important to consider how they participate in making place. Thus, the maps must be examined within a key tradition in rhetorical/humanistic geography: The rhetorical construction of place. For Tuan $(1976,1979)$ space refers to the endless, vast freedom of movement, the lack of "rootedness" felt when one encounters an external world free from herself. Place, on the other hand, is security, the place of "rootedness" where one's personal and ancestral history have tied her to a geographical location. Tuan (1976) claims "Place is security; space is freedom: we are attached to the one and long for the other" (p. 3). By attaching an identity to a particular location, that individual is locating a geographic home for his or her sense of self. In other words, "place incarnates the experiences and aspirations of a people. Place is not only a fact to be explained in the broader frame of space, but it is also a reality to be clarified and understood from the perspectives of the people who have given it meaning" (Tuan, 1979, p. 387).

It is important to recognize, then, that transforming space into place and endowing it with human feeling is a decidedly rhetorical process. Place is constituted in the various discourses of individuals, activist groups, urban planners, and, in the case of this thesis, countermaps on Google Earth. It involves language, symbol use, and an overall placement of often heavily ideological and political meanings into the landscape. In other words, to study place-making is to address the means by which individuals and organizations, each with their own motives, take space and transform it into place "redolent with cultural meaning" (Routledge \& Cumbers, 2009, p. 82). As Stewart and Dickinson (2008) state, "In real ways, place does not exist without the human efforts necessary to turn space into place" (p. 283).

A full review of the research on place and its rhetorical construction is beyond the scope of this essay. It has been vital to research in geography (e.g., Buttimer, 1976), sociology (Alkon \& Traugot, 2008), and communication studies from both a social scientific (Cantrill, 1998) and rhetorical perspective (Blair \& Michel, 1999). Most rhetorical scholars have been concerned with the use of place for directing public memory (Blair \& Michel, 1999; Dickinson, 1997), rhetorical attention (Zagacki \& Galagher, 2009), or promoting national identification (Clark, 2004). Oftentimes, one place is treated as a material rhetorical text. Specific places have included, among others, Old Pasadena (Dickinson, 1997), Route 66 (Wood, 2010), and the United States west coast (Lagervist, 2008). What all of these studies have in common is a recognition that place is more than just a context or background for action, but is in and of itself the locus and product of rhetorical activity, composed of divergent traces of symbolic action. 


\section{Place and organizational rhetorics of social change}

One line of research particularly useful to this essay addresses how the construction of place figures into the rhetorical discourses created by organizations seeking global social change. Routledge and Cumbers (2009) provide a useful launching point:

Place, then, is important to sites of resistance, the creation of alternative knowledges and the interplay between local and global practices. Places comprise an interwoven web of specific symbolic meanings, communicative processes, political discourses, religious idioms, cultural practices, social networks, economic relations, physical settings, envisioned desires and hopes. Sensitivity to such processes when considering particular practices of resistances acknowledges the subjective nature of people's perceptions, imaginations and experiences when they are involved in political action. It locates such action in dynamic spatial contexts, as it sheds light upon how spaces are transformed into places redolent with cultural meaning, memory and identity under conditions of conflict. (pp. 81-82)

This is a useful perspective on the relationship between place and organizational social change rhetorics. Viewing place as a web of symbolic meaning inherently influenced by articulations of oppression and resistance allows one to realize that organizations may weave their own meanings into place for the purposes of motivating collective action.

Research has supported this claim. Keith and Pile (1993b), for instance, state that the Docks in London were created as a place that embodied a multitude of meanings necessary for organizing labor disputes and resisting class politics. Dempsey, Parker, and Krone (2011), following Lefebrve (1991), argue that the discourses of transnational feminist networks are dominated by the construction of counterspaces at various scales. ${ }^{2}$ The means by which the geographic imaginary is created as a counterspace will inhibit or make possible the articulations of local place-based differences while networking for global action. Both of these essays share a common belief: The production of resistant places is vital to the articulation of collective action.

\section{Place-framing: The production of place and collective action}

In a similar vein, Martin (2003) argues that the relationship between the production of place and organizational rhetorics can be conceptualized as "placeframing." Martin (2003) argues that "organizations discursively relate the conditions of place - the common experience of people in place - to their different agendas" and in doing so "they construct the local ... as the appropriate sphere for collective action" (p. 731). This perspective is inspired by work on collective action framing (Benford \& Snow, 2000; Sandberg, 2006). Sandberg (2006) defines collective action frames as "action-oriented sets of beliefs and meanings that inspire and legitimate social movement activities and campaigns" (p. 211). Collective action framing consists of three primary activities - diagnostic framing (detailing a problem in reality), prognostic framing (providing solutions to 
that problem), and motivational framing (offering a motive for participating in the prognostic solution) (Benford \& Snow, 2000). Martin (2003) argues that an organization's rhetorical construction of place can assist in all three of these framing activities: diagnosing a problem, offering a prognosis, and motivating action.

Martin (2003) uses four neighborhood organizations in Minnesota as case studies, explaining the diagnostic place-frames produced by these organizations addressed "what the neighborhood should be like if it had no problems" (Martin, 2003, p. 739). This allowed the organizations to describe those elements that seemed out of place so as to constitute a problem in the geography. The prognostic frames focused on the means by which future-oriented human action worked to restructure the place and alleviate the diagnosed problem. Finally, Martin (2003) says that "motivation place-frames should refer to the daily life experiences residents are likely to have in the neighborhood in order to foster recognition of their location-based commonalities" (p. 736). Those components of place that are most salient to the organization's agenda may be highlighted in order to address common desire for action. Thus, working from a common identity regarding their place (motivational frame), and illustrating the problematic features of that place (diagnostic), they hoped to construct place out of space in such a way as to gather support for their association's vision for improving the future landscape (prognostic). In constructing collective action, place becomes the locus of rhetorical strategy.

This essay proceeds within this tradition of research that argues that the social and discursive construction of place can be fundamental to organizational social change rhetorics. Specifically, I use Martin's (2003) conceptualization of placeframing as based upon diagnostic, prognostic, and motivational frames to analyze the World is Witness map produced by the USHMM. By extensively traveling the map and providing a close reading of the verbal and visual rhetoric mapped onto satellite images of local spaces, I seek to understand how the map frames the local places of Africa in a way that attempts to motivate global collective action. However, I attempt to extend this research, among other ways, by focusing on a unique form of discourse (countermapping) on a unique medium (Google Earth) which presents unique questions about the construction of place. Specifically, I argue one addressing countermapping on Google Earth needs to understand how a strategy for framing local place either reinforces and is reinforced by or disrupts global politics of viewing spatial satellite imagery.

\section{Google Earth and the Politics of Viewing}

A growing body of recent scholarship suggests that Google Earth has some inherently positive benefits. These benefits include educational enlightenment (Butler, 2008; D'Agnese, 2007; Lund \& Macklin, 2007) and the enhancement of environmental advocacy (Dicum, 2007; Ewalt, 2011). The medium has proven to be a useful resource for visualizing the various geographies at the core of rhetori- 
cal messages created by environmental justice groups. For instance, the medium has proven useful for the Amazon Conservation Team, which "uses Google Earth to monitor illegal mining and logging in the Amazon basin" (Dicum, 2007, p. 60). The rapid response from human and environmental rights organizations is the result of a larger desire to use Geographic Information System (GIS) technologies for illustrating the spatial dimension of social oppression. As a highly accessible, user-friendly program, Google Earth places these otherwise complicated and technical GIS programs in the hands of ordinary citizens (Dicum, 2007). In this sense, it has a great deal of populist rhetorical potential.

Nevertheless, Google Earth is still perceived as a force contributing to political disparities around the world. The medium is often viewed in light of government secrecy and surveillance. It is seen as contributing to global disparities by way of its exclusion of certain spaces and humanity from its satellite view (Stahl, 2010). Citizens have even revolted against Google cars taking pictures of local spaces, thereby attempting to resist the politics of viewing associated with the medium (Gang, 2009). In fact, even the initial image of the medium (the view of the Earth floating in space) has a discursive connection to the aesthetics of the Apollo 14 photographs and religious modernism, which, as Cosgrove (1994) argues, is foundational to an imperialist geographical imagination.

Providing a more detailed account of the politics of viewing associated with Google Earth, Stahl (2010) argues that the medium of Google Earth is unable to rid itself of its military aesthetic history. The images of Google Earth were used heavily by the news media covering the invasion of Iraq. Among other arguments, Stahl (2010) states that the aesthetic of Google Earth in wartime discourse did not enlighten the public, but "functioned almost purely for its own spectacular and fetishistic value, a demonstration that American journalists, like the American military, held the 'big guns' “ (p. 79). Furthermore, Stahl (2010) argues that Google Earth as a rhetorical aesthetic "positioned the citizen as a war-consumer, immersed in a seductive array of libidinous images that aligned the subject with a war machine-in-motion," and that it "worked to captivate, capture, and colonize the subject while submerging the deliberative impulse" (p. 82). Similarly, Harris (2007) argues that Google Earth, as it has been embedded in a discourse of militarism, constructs a colonial subject reinforced by the Apollonian gaze and the digital divide (in part informed by the "I can watch you, but you cannot watch me" assumptions of politicized viewing). Finally, Parks (2009), although generally appreciative of the power of satellite imagery to institute public dialogue, contributes to the argument that Google Earth contains a politics of viewing by stating "Google Earth is not a 'view from nowhere,' - it is the view from a company with enormous visual capital" (p. 542).

Thus, while Google Earth has proven to be a valuable resource for social change organizations, the medium also brings with it a politicized, militarist, and capitalistic history that produces the subject behind the computer screen as simultaneously a citizen war-consumer and one who has the power of the digital divide to embody the viewing position of the colonizer in advanced capitalism. In other words, it can be argued that any rhetorical value of the medium should be consid- 
ered in tension with an ideological politics of viewing. ${ }^{3}$ Because of this, I approach the relationship between countermapping, place-framing, and Google Earth from a different direction than those essays before this one. Parks (2009) argues that the "satellite image is useful as a site/sight of focus because its abstraction and indeterminacy keeps acts of interpretation and practices of knowledge dynamic" ( $p$. 538). She argues that the Crisis in Darfur application on Google Earth is problematic precisely because it undermines this view of satellite spatial imagery with images of African tragedy. I argue, however, that given the politics of viewing on the medium, in order to understand to what extent countermapping on Google Earth is capable of motivating social change, one can question whether or not the maps are able to disrupt the aesthetic history of the medium's construction of a political subject. Can the way local place is framed on the World is Witness map disrupt this subject position? Can the mapping rhetoric of USHMM create a disruption, a fissure, a break in the colonialism of the subject that will allow for motivated placebased collective action? To address Google Earth requires addressing these questions and, thus, it allows for the extension of place-framing literature by arguing it may not be just the evocation of a sense of place, as Martin (2003) argues, but the very construction of the map-user as space-bound motivated subject that becomes the conditions of motivated place-framing. I now turn to my analysis of the World is Witness map to illustrate these points.

\section{The Embedded Injustice Frame and the Construction of the Global Witness}

The USHMM has two maps by which they support their interactive cartographic efforts on Google Earth: the World is Witness and Crisis in Darfur maps. While I am primarily concerned with the World is Witness map, it is important to recognize that users are likely to travel the spaces included in both cartographies and, thus, I will devote some attention to the Crisis in Darfur effort as well. The World is Witness map primarily provides narratives and photographs tied to various geographic spaces that provide information on African genocide, particularly that of Rwanda. The USHMM explains, "World is Witness enables citizens to bear witness to threats of genocide and related crimes against humanity, using the web and Google Earth" (Graham, 2007, June 1). Using the map to direct spatial travels on Google Earth, the individual follows links marked with a symbol of a head against a blue backdrop with various titles such as "Goma on the Edge," "Crises in the Kivus," or "The Most Beautiful Hill in Rwanda." Clicking on any of the links presents the photographs and journals of traveler, photojournalist, and employee of the USHMM, Michael Graham, chronicling a virtual experience of traveling through Rwanda and the Democratic Republic of Congo. In addition, each time a link is clicked, the virtual Earth moves to a new location and the Google Earth user is positioned to view the landscape from a predetermined distance. Meanwhile, the related Crisis in Darfur map is dedicated to stories and photographs of victimizations directly related to the atrocities facing Darfur. ${ }^{4}$ In what follows, I argue that the World 
is Witness map frames place as a space of "Embedded Injustice" and constructs the Google Earth-using subject as a global witness. Similar to Parks' (2009) argument that the Crisis in Darfur application is a discourse that reproduces assumptions of African tragedy, I argue the World is Witness map frames place as inevitably a landscape of violence and destruction, thereby creating a commensurate prognostic frame, which advocates global entrance into place in order to "bring these spaces into focus." In other words, while this map provides important information on excruciatingly despicable acts of human injustice, the way it frames place positions the African continent as one of embedded injustice and is limited in its ability to disrupt the politics of the colonizing subject and advocate place-based action. Place is framed not to support the agency of the local, but the power of the global.

\section{Diagnostic place-framing}

Place is diagnosed on this map by tying a verbal rhetoric of destruction and violence to concrete images and descriptions of the landscape. To support this, I first focus on the icon entitled "Goma on the Edge" located in the Democratic Republic of Congo. Upon arrival at this icon, the user is positioned far enough from the virtual earth to view the presence of a mountain next to the icon. The spatial positioning seems to make the space itself a point of rhetorical invention for diagnostic framing. The icon states, "In 2002, the volcano Nyiragongo erupted and sent molten lava flowing through the airport, city center, and into Lake Kivu. The city was rebuilt on top of the hardened volcanic rock, and at times I could almost imagine we were driving on the moon" (Graham, 2007, December 2). The caption then proceeds to discuss the violence and destruction influencing the area. The nature of violence and injustice (diagnosed problem) is tied to the very essence of its material spatiality (creation of place). The volcanic eruption has instituted barrenness into space, no potential for vibrant life. In this sense, the death inherent in the material spatiality underlies the very diagnosis of problems of death and injustice. This interpretation is reinforced by and reinforces the viewing perspective of Google Earth, which presents the satellite imagery of what is now interpreted as a volcano left of the icon.

Another example is contained as one makes two spatial movements from "Goma on the Edge," encountering the icon "We Sleep on Stones." The caption begins, "the sound of exploding shells mixes with afternoon thunder; only those who live or work here can tell the difference" (Graham, 2007, December 5). The essence of gunshots is rhetorically associated with the objective features of the space: thunder and climate. Thus, we have a rhetorical association between the diagnosis of a problem (gunshots) and the natural features of space (climate). In addition, we are told that only residents can distinguish these sounds. From the global, however, this is not possible. This is important as the Google Earth user is never moved, after clicking on the icon, to feel completely placed in the locality. The user is still gazing upon the landscape from a distance, from the eye in the sky. Thus, the map reinforces this global subject position and in doing so suggests from that position, the diagnosed problem of battles over human rights (the gunshots) are intricately connected to the place, landscape, and locality (thun- 
der/weather/essence of space). The diagnostic problem is embedded into the landscape.

This diagnosis of place is reinforced throughout the map. The mapping icon entitled "From a Thousand Hills" presents a verbal rhetoric of injustice and violence as the timeless mode of interpreting Rwanda's spatiality:

Rwanda is a land of a thousand hills, a tiny vividly beautiful country in central Africa, home to some of the world's last remaining Mountain Gorillas. But it also will be forever known as the place where, in 1994, genocide consumed every hill and corner, bodies clogged the rivers, and the "international community" turned away. (Graham, 2007, November 23)

The injustices done to human rights have been inscribed and fixated in the landscape. While the rivers in Rwanda are beautiful, they will forever be seen as rivers filled with bodies. As such, the material spatiality is the very foundation for diagnosing place-based injustice.

Finally, perhaps the most powerful example is the visual and verbal rhetoric mapped into Nyamata, Rwanda. Here, the mapping text is entitled "Day Becomes Night." The text presents an image of what appears to be very peaceful stars against a black sky with a darkened statue of the Virgin Mary hanging forlornly on the brick walls. The lights on the wall seem to make a cross to the right of the screen. The caption reads:

For an instant, I saw the night sky - a thousand points of light on a dark canvas, the Milky Way, Orion's Belt-but it was almost noon, and other details forced me back to reality: blood stains on the walls and bullet holes in the Virgin Mary; a smashed alter and an iron door twisted nearly off its hinges. My "stars" were thousands of tiny holes punched into the tin roof by grenade shrapnel. (Graham, 2007, November 25)

Again, this reinforces the association between crimes against humanity (bullet holes/grenades) and the natural features of the space (stars) in order to construct a diagnostic vision of the problems facing local place as embedded injustices.

Overall, these examples illustrate the diagnostic place-framing of the embedded injustice map. If injustice flows with the rivers, if the stars are bullet holes, the gunshots thunder, and volcanoes create a barrenness where only death is possible, then it seems the very material features of the spatiality diagnose the problem to be countered. While the diagnosis of injustice as embedded in material spatiality poses potential colonialist-infused problems in and of itself as it essentializes spatiality as one that will never escape its own struggle, ${ }^{5}$ it is also problematic as it opens up a space for advocacy of solutions that support politicized viewing. To support this argument, it is important to turn to some prognostic features of the map. 


\section{Prognostic framing}

As Martin (2003) illustrates, the prognostic portions of place-framing deal with those portions of the place that can be changed to make the place fit the goals of the organization and its collective vision. Interestingly, if the place is constructed as a locality that is naturally experiencing the problems of human injustice, then a commensurate prognostic frame is one that promotes global alteration of the place as the local is limited in its ability to manifest the necessary collective action. If the diagnostic problem is materialized in the landscape, the place itself must be influenced by outsider action. The map supports this prognosis by advocating two solutions: Bringing into focus the ignored geographies of the world and by philanthropic behaviors of global citizens of the West. ${ }^{6}$ This prognosis, and its celebration of entrance into local place for the sake of photographic clarity, which is made possible by the designation of injustice as inherently and forever embedded into material spatiality, reinforces and is reinforced by the politicized viewing of Google Earth users.

The map, when offering a place-based prognosis for its problems, often suggests that the local place requires the entrance of global citizens into the geography of injustice. For instance, one mapping location on the World is Witness map has an icon entitled "Roadblocks." At this icon, a visual image is presented portraying the back of a young, presumably African, man walking through an African space. Underneath the image, the caption reads:

With the help of a courageous American aid worker named Carl Wilkens (almost certainly the only American to stay during the entire genocide), Damas protected more than 400 children and Tutsi adults, hiding them above the ceiling and under beds. Known to the militant as a Hutu, he had no reason to risk his life to help strangers. For my friend Gasana's sake, deeply traumatized but alive, I am forever grateful he did. (Graham, 2007, November 24)

Here, the map-user is presented with a prognosis for a place-based solution: courageous action. However, Damas (originally from the local place) cannot do it alone. Instead, he needs Carl Wilkens (the American aid worker - the global outsider) to assist in the struggle. The local place, as it is materially informed by injustice, needs to be infiltrated by those affiliated with global outsider, perhaps Western spaces. In other words, the place needs to be infiltrated by the user of Google Earth, the one behind the politicized, powerful gaze.

Another icon that seems to visually support this verbal anecdote of the courageous, philanthropic Western hero, bringing the local place into focus, is located at Bukavu, Democratic Republic of Congo and is titled "Crisis in the Kivus." There is an odd picture that accompanies this icon. Unlike most of the visual photographs that seem to diagnose place, there is no picture of a suffering local. There is no focus on a saddened set of eyes, or a tired-looking, frail body struggling through a locality that is meant to contextualize our interpretation of the satellite spatial imagery. Instead, this picture seems to provide a prognosis for place. The only image of what seems to be local citizens is placed in the background, around 
a small fire, out of focus, an anomaly for the map which primarily provides intimate direct images of suffering African faces. In focus, in the foreground, is the arm of a white male with his sleeves rolled up, holding a pen in his right hand, seemingly ready to write. He has a camera strap around his neck, but you cannot see his face. One way to interpret this image is from the prognostic standpoint. It seems to suggest that outsiders, writing about and photographing the injustice embedded in the space, have the ability to change the place, to "bring it into focus." The white man with the camera strap is positioned to be able to bring the citizens around the fire behind him into focus.

This interpretation of the visual image is further supported by the hyperlinks beneath the picture, contextualizing the imagery. These allow the user to travel beyond the map to the work of Western heroes who have used their pens and cameras in the past to bring into focus the local place-based injustices. Google Earth users are invited to "read traveling companion Michael Gerson's column from his trip in the Washington Post" as well as "visit Angelina Jolie and John Prendergast's interactive journal on the Museum's website to witness what they saw and heard during a 2004 trip to Eastern Congo" (Graham, 2007, November 28). In short, the user is invited to experience the local place vicariously from the perspective of the courageous American. Importantly, both of these links focus on instances where a global outsider has entered the local place and captured images of injustice, making it global alteration that is the best place-based solution. As such, the map provides prognostic place solutions that involve the power of the global, thereby making the map unable to disrupt the politics of viewing on Google Earth.

It is important to point out that this prognosis is present on the USHMM's mapping of the Crisis in Darfur as well. ${ }^{7}$ The Crisis in Darfur map contains a number of photographs mapped to different locations in the region to indicate the injustice occurring there. As Parks (2009) usefully indicates, most of the photographs do not have a date, playing into a public memory of Darfur as only defined by local victimization, absent of complex global colonialist histories (Parks, 2009). However, there is another feature of these photographs useful to this analysis of prognostic framing: The presumption that the crisis needs to be brought into focus and that this activity is primarily the product of global entrance into local place. For instance, the photographs offer close-up images of African tragedy, with brief captions that read similar to "In the tiny medical facility of Goz Beida, three men lay side by side, their eyes gouged out by the Jenjaweed knives." Another icon shows an image of two women, whose faces can barely be seen with a caption that reads: "Women are interviewed by physicians for Human Rights Investigators. These women told stories of the destruction of their livelihoods and exposure to rape as their villages were being attacked." Almost all of the photographs only identify the individual as "SLA Rebel," or "A Woman," and provide their story of victimization. All of these photographs seem to share the same presumption of bringing African tragedy into focus: All that is needed is the use of the photograph to provide an image of African injustice without description of time or person, only a vague inscription of the nameless victim into the timeless 
place. (It is excruciatingly important to point out that the World is Witness does a very fine job of incorporating the individuality of local individuals, which is a place for potential disruption of Google Earth politics of viewing. The Crisis in Darfur map, however, often does not).

However, there is one indication of individuality on these images, and this plays into the presumption that global entrance into local place allows for the bringing of the place into focus as a prognostic solution. While there is no identification of the victim in the picture, there is credit to what the World is Witness map would call the "courageous individual" who took the picture. For instance, we are told that the first example was a photograph taken by actress "Mia Farrow" and the second was taken by "Michael Wadleigh." The photographs, then, simply reinforce the map user's affiliation with global dominance by supporting the colonial, war-consumer, capitalist perspective of satellite imagery with photographs that construct local place through the lens of famous Western actors and photographers. The prognostic solution associated with place is less based on the "local ... as the appropriate sphere of action" (Martin, 2003, p. 731) and instead on the global entrance into place.

As the discussion has proceeded thus far, the first two portions of the placeframing of this map can be read as follows: Invasions of human rights and injustices are embedded in the very spatiality of the African continent (diagnostic). Because of this, place needs to be brought into focus and altered and, to do so, requires global entrance into the spatial locality from beyond the local place and, perhaps particularly, from the philanthropic behaviors of the Western world (prognostic). One cannot, and should not, say that the images and verbal captions constructing these two portions of the frame are not moving, or that the emotional appeal is not powerful, or that the USHMM is not doing a global good in constructing these maps. However, one should be critical of the association of injustice to physical features of the landscape as this constructs the presumption that injustice naturally occurs in Africa, which may reinforce colonial assumptions. In addition, to answer one of the central focuses of this essay, one should be aware of the limited ability of this type of place-framing to disrupt the politicized viewing associated with Google Earth subjectivity. That is, for the mapping to serve its purpose, the way it constructs local place as playing a part in global struggles will likely need to disrupt the "I can watch you, but you can't watch me" assumption of Google Earth map-using. However, framing local place to embed injustice in Africa, which opens up the need for global entrance into place to view and photograph the victims, reinforces the politics of viewing spatial imagery. This is particularly true as the victimization and violence is inherently embedded in the landscape. Thus, to view the landscape of African spaces even from a Google Earth distance is to bring the image of struggle into focus, thereby constructing the Google Earth-using subject as the very globally focused courageous Western hero who needs to enter local place and assist with action. Such a perspective offers a view of global action that reinforces and is reinforced by the politicized viewing behaviors of Google Earth users. 


\section{Motivational place-framing}

It is this construction of the subject as globally motivated from a safe viewing distance that is the crux of the map's motivational framing. I argue that the primary means by which this World is Witness map conducts motivational placeframing is not by facilitating "a sense of place" and appreciation for the local, as Martin (2003) argues, but by constituting the Google Earth-using subject as a globally motivated witness. This is done by spatially positing the auditor a viewing distance from place and reinforcing that distance through verbal and visual rhetoric. Thus, it is not just how the organizational rhetoric convinces the subject to act on behalf of place, but how that very rhetoric brings the subject into existence as one capable of action.

Specifically, as the title of the map indicates, the subject position is brought into existence as a witness. I define a witness as he or she who has seen and is empathetic toward local place-based injustice, but is still consistently aware of his or her position outside of the locality. This subject position is a variation of what Slade (2007) termed the "survivor ethos." 8 For Slade (2007), the survivor ethos is "one who is living who should be dead and hence given testimony, however partial it may be, to the events of death that passed them by" (p. 86). The survivor, thus, is a rhetorically constructed subject position detailing one who has nearly experienced death and is now able to testify to its existence and, as such, has a responsibility to testify. Slade (2007) argues that this is a primary subject position experienced during the postmodern era. The witness is a similar subject position as the survivor. The witness has seen death and injustice (thanks to Google Earth), and is able to testify to that injustice and, in fact, has a responsibility to testify. However, the witness always maintains his or her association with the outside as the witness has not survived the injustice. The survivor inherently contains a sense of place, whereas the witness contains no presumption that she or he has lived through place-based injustice. Thus, motivation is not constructed by emphasizing the commonalities experienced in local place (Martin, 2003), but by reinforcing relationships to global spatiality.

This subject position is constructed throughout the map. As the icon at Washington, DC, which introduces the map, states, "World is Witness enables citizens to bear witness to threats of genocide and related crimes against humanity, using the web and Google Earth" (Graham, 2007, June 1). As Google Earth allows the user to bear witness, the user of Google Earth is created as the witnessing subject. In addition, icons such as "From a Thousand Hills" state that, with past genocides, "the 'international community' turned away." Turning away implies having first seen the destruction and then having done nothing. In essence, citizens of the global world witnessing the death and destruction denied their responsibility and agency for action. The witness subject position, after having seen, is now in a position for motivated action. However, as stated, unlike the survivor's ethos, a position of greater testimony, the witness does not imply having lived through the destruction in the local place. It merely implies having viewed. This subject position becomes entirely possible when using the medium of Google Earth. The user can view the destruction, but has not lived it. The subject is always safely po- 
sitioned at a distance from the local place and the map's rhetoric reinforces this position through the rhetoric of witnessing.

The witness must be positioned as outsider to place and, more specifically, as the benevolent global visitor. As stated, the World is Witness maps the places of Rwanda and the Democratic Republic of Congo, among other local places, from the perspective and travels of outsider Michael Graham. The Crisis in Darfur offers photographs mapped onto the landscape that offers an experience of place from the perspective of Mia Farrow and Michael Wadleigh. The user of Google Earth when confronting injustice is not allowed to forget his or her global affiliation. The user is not a place-inhabitant or survivor; the user is a global outsider who is capable of perceiving places of suffering without ever having to face the implications of his or her affiliation with outsider space and the politics of viewing.

\section{Conclusion}

In this essay, I have provided a reading of the World is Witness countermap (and, at times, its affiliated map, the Crisis in Darfur) as a place-framing organizational rhetoric. I argued that this map frames place as one of embedded injustice, which promotes solutions based on global entrance into place, and constructs the Google Earth user as a witnessing outsider. This subject position is distinct from that of the survivor as it is always an outsider to place, a perspective that is reinforced by the satellite imagery of Google Earth. I have further argued that all three of these features of the framing of local place may fail to disrupt, break, or provide an opening for social change in the material body of the Google Earth-using subject. Because the map embeds injustice into the very spatiality of the African continent (diagnostic place-frame), encourages global entrance into place (prognostic place-frame), and constructs a global subjectivity (motivational frame), the map may unintentionally reinforce colonial perspectives (injustice is natural to African space) that are already present in the use of Google Earth. In short, as it currently exists, this map and its framing of place does not seem to undermine the perspective offered by Google Earth - a perspective mediated by the vast technological networks, the class-based access to technology, and global disparities that pervade the medium - but reinforces that Google Earth-inspired position through its particular framing of place.

In making this argument, this essay attempts to extend research and theory in a number of ways. First, I have attempted to extend the work on how place can be constructed in organizational rhetoric to support collective action. Most research has illustrated how places can be constructed from space to organize actors around common place-meanings, thereby motivating social change (Keith \& Pile, 1993b; Martin, 2003). I have extended this work first by focusing on a unique form of rhetoric (countermapping) on a unique medium (Google Earth). Moreover, I have attempted to illustrate that place can be framed on countermaps for the purposes of organizing outside map-users as opposed to organizing those 
who reside in the place. The maps of the USHMM do not map space, and create place, in order to organize collective action on the part of locals. Instead, they do so to encourage global entrance into the local place. This is a different perspective than those offered by previous accounts of place and organizational rhetorics. It is not that place is constructed to emphasize commonalities and thereby motivate action, but the point seems to be to construct local place as the other from which global affiliation is interpreted as the source of motivated agency.

In addition, I have attempted to extend research on Google Earth, countermapping, and place-framing. First, I extend countermapping and Google Earth research by focusing on the intersection between these two contexts of discursive action. Specifically, I attempt to explain how the interaction between mapping and medium may reinforce the politics of viewing inherent on the medium. The research on countermapping has yet to attend to the specifics of countermapping as a placeframing activity influenced by verbal and visual rhetorical strategy. ${ }^{9}$ Furthermore, while there have been a few recent insightful rhetorical and discursive critiques of Google Earth (Parks, 2009; Stahl, 2010), neither of these analyses attends to the countermapping on the medium as an organizational rhetoric of social change nor how they specifically socially and discursively construct place in order to frame the organization's social change efforts. I have attempted to argue that the very possibility of the effectiveness of the countermapping enterprise on Google Earth is dependent upon its ability to disrupt the politics of viewing spatial satellite imagery. While certainly one can take the alternative view -Google Earth is inherently an egalitarian attempt to equalize access to sophisticated GIS technologies - I have attempted to present an argument that highlights a fresh perspective on both countermapping and Google Earth in order to advance nuanced and hopefully useful questions regarding the medium's activist potential. Finally, I have attempted to elucidate one overlooked feature of framing: Motivational framing is not simply the process of providing logical reasons for action, but also constituting the subject as one capable of motivated action.

However, despite any potential contribution to academic debates, I hope this essay provokes complicated questions both specifically about the World is Witness map and countermapping on Google Earth more generally. Regarding the World is Witness, a more useful mapping of place may be one that rhetorically disrupts the politicized act of viewing on Google Earth. To do so would involve asking a few questions about the strategic use of the medium. First, how can mapping on Google Earth provide information that is effectively self-reflexive about the colonial politics of the very medium it is using? As Parks (2009) indicates regarding the Crisis in Darfur map, it would be useful for this map to include information about colonialism influencing the African continent. However, Parks (2009) believes that satellite imagery is still beneficial, when left to its own visual capabilities, to the pursuit of global dialogue. I agree that information about colonialism, capitalism, and global politics in Africa would be useful for these maps (for a useful critical chronology of the influence of colo- 
nialism on the Rwandan genocide, see the supplementary features to American Radio Works' documentary Justice on Trial available on the organization's Web site, American Radio Works, 2011). However, I believe that very usefulness is due to the capabilities of rhetorical information to break the unity of the politicized viewing subject, thereby using place-making information to reflect on the colonialism contextualizing Google Earth.

Second, if mapping is to mobilize people in a local place, one must ask: How can mapping reflect the multiplicity of experience and voices that make place, while networking spaces for social change? To answer this question would involve addressing how the resources of mapping can be used to frame place in order to empower the agency of the local-through a plurality of local voices - as opposed to mobilizing the resources of the global. American Radio Work's Justice on Trial radio report is an interesting example of explaining the multiplicity of the Rwandan experiences regarding genocide, explaining non-Western systems of justice, highlighting different voices and opinions on that system, and incorporating local music (Buzenberg, 2002). All of this information is provided without relying on satellite spatial imagery. Additionally, organizations such as WITNESS, which is dedicated to building the capacity of local human rights groups' use of video technologies, may provide a useful example for how to develop agency in local places through common technological resources (WITNESS, 2011). Google Earth Outreach does work - in a similar form as WITNESS - with local groups to develop their mapping activities. However, given the medium's history of affiliation with global power, one should question whether the use of the medium will always inhibit the efficacy of such efforts. While I have primarily focused on one map, future research will hopefully address whether any of the locally produced maps on the medium are able to disrupt the medium's historically embedded ideological politics of viewing.

In the end, a few questions still remain that should be taken up by academics and social change activists in order to contribute to a broader debate: Is countermapping activity on Google Earth ever capable of instituting ruptures in the body of the Google Earth user, thereby disrupting the politics of viewing satellite spatial imagery? Does this medium have such control over the construction of the subject that the rhetorical activity on the medium is forever limited by the politics of viewing spatial satellite imagery? If not, what specific rhetorical tactics can create local place in such a way as to allow for a more successful rearticulation of the Google Earth subject? How can the medium move beyond witnessing and evoke the politics of the subject-survivor? Or should it? In the example put forth in this essay, the World is Witness map provides extremely critical information and the USHMM should be praised for their social efforts. However, the "embedded injustice" place-framing is never able to escape the very politics of the medium on which it works and therefore reinforces and is reinforced by a colonial, Western, corporate-infused politics of viewing. 


\section{Notes}

1. In viewing these cartographies as "organizational rhetorics," I am working within a growing body of literature that broadens the conceptualization of what counts as an organization-moving the study of organizational communication practices beyond the workplace - to include the study of organizations participating in the promotion of social resistance (e.g., Cloud, 2005; Ganesh, Zoller, \& Cheney, 2005; Norton, 2009; Papa, Singhal, \& Papa, 2006). In addition, in calling these cartographies "organizational rhetorics," I am working within a body of literature that recognizes individual rhetors are often speaking on behalf of an organization, working within the constraints of that organization (Cheney \& McMillen, 1990). In the case of the World is Witness map, while Graham is an individual responsible for much of the rhetoric, the persuasive material is presented, funded, and produced, in cooperation with Google Earth outreach, by the USHMM.

2. The concept of counterspace is informed by the work of Lefebrve (1991) and his statement, "Change life! Change society! These precepts mean nothing without the production of an appropriate space" (p. 54). Counterspaces can also be thought of as the process of producing places of resistance.

3. Elsewhere, I have taken a more optimistic look at viewing on Google Earth (Ewalt, 2011). I do not necessarily think that it is impossible to hold opposing views and in fact find it quite useful to explore arguments related to both sides of a complex issue like using Google Earth for social change.

4. A note on method: In performing my frame analysis, I focus on the direct icons linked to the virtual spaces of Google Earth. However, while at times it will be important to indicate the nature of external links to websites, I do not travel these links as part of the analysis. Instead, I am looking for the rhetoric the user actually experiences when actually in that virtual place. It is also important to recognize that this analysis represents one attempt to read the map's verbal and visual rhetoric, using place-framing as a guiding concept. This means that, while I have attempted to remain thorough in my analysis, not every feature of the maps are covered in this analysis; rather, those verbal and visual features that more or less seem to centrally participate in the framing of place are highlighted. The occasional visual critique is guided by my interpretation of the photographs, while keeping in mind the three-part categorization of place-framing. Because of this, there are other ways to read these maps, and other interpretations are possible and welcomed. This is simply one possible reading that I feel opens up useful questions regarding countermapping on Google Earth.

5. This is supported by Parks' (2009) argument that the Crisis in Darfur application on Google Earth presents representations of Africa as always influenced by tragedy and violence.

6. Parks' (2009) assessment of the Crisis in Darfur map illustrates a similar argument. She says the discourse surrounding the release of this application uses a metaphor of shedding light on these areas of injustice in Africa, which may reinforce colonialist assumptions of Africa as the "dark continent."

7. While I am focusing on the World is Witness in this essay, and Parks (2009) already provides a useful discourse analysis of the Crisis in Darfur, it is important to indicate the presence of this map as users of Google Earth may be likely to travel between the spaces of both maps. 
8. Elsewhere, I have argued that Google Earth actually evokes the survivor's ethos through the act of using it (Ewalt, 2011). While I still believe that this may be possible, I feel that the rhetoric of witnessing conditions the subject away from the feelings of survival as explained throughout this section on motivational place-framing.

9. The closest attempt is Barney's (2009) extremely insightful analysis of the Pluto Project. However, Barney (2009) is primarily concerned with the subversion of cartographical form as opposed to the construction of material place, and is not concerned with how these rhetorical strategies work to frame place and collective action.

\section{References}

Alkon, A. H., \& Traugot, M. (2008). Place matters, but how: Rural identity, environmental decision making, and the social construction of place. City and Community, 7, 97-112. doi: 10.1111/j.1540-6040.2008.00248.x

American Radio Works. (2011). Chronology of a genocide: Timeline of events in Rwanda. Retrieved May 15, 2011, from http://americanradioworks.publicradio. org/features/justiceontrial/rwanda_chronology.html

Barney, T. (2009). Power lines: The rhetoric of maps as social change in the post-Cold War landscape. Quarterly Journal of Speech, 95, 412-434.

Bauer, K. (2009). On the politics and the possibilities of participatory mapping and GIS: Using spatial technologies to study common property and land use change among pastoralists in Central Tibet. Cultural Geographies, 16, 229-252. doi: $10.1177 / 1474474008101518$

Benford, R. D., \& Snow, D. A. (2000). Framing processes and social movements: An overview and assessment. Annual Review of Sociology, 26, 611-639.

Blair, C., \& Michel, N. (1999). Commemorating the theme park zone: Reading the Astronauts Memorial. In T. Rosteck (ed.), At the intersection: Cultural studies and rhetorical studies (pp. 29-83). New York: Guilford Press.

Butler, D. (2008). Having fun with Google Earth. Mathematics Teaching Incorporating Micromath, 209, 28-30.

Buttimer, A. (1976). Grasping the dynamism of the lifeworld. Annals of the Association of American Geographers, 66, 211-292.

Buzenberg, B. (Producer) (2002, July). Justice on trial. [Radio broadcast]. Saint Paul, MN: American Public Media. Retrieved May 15, 2011, from http://americanradioworks.publicradio.org/features/justiceontrial/index.html

Cantrill, J. (1998). The environmental self and a sense of place: Communication foundations for regional ecosystem management. Journal of Applied Communication, 26, 301-318.

Cheney, G., \& McMillen, J. J. (1990). Organizational rhetoric and the practice of criticism. Journal of Applied Communication, 18(2), 93-114. doi: $10.1080 / 00909889009360318$

Clark, G. (2004). Rhetorical landscapes in America: Variations on a theme from Kenneth Burke. Columbia, SC: University of South Carolina Press.

Cloud, D. (2005). Fighting words: Labor and the limits of communication at Staley, 1993 to 1996. Management Communication Quarterly, 18, 509-542. doi: $10.1177 / 0893318904273688$ 
Cosgrove, D. (1994). Contested global visions: One-world, whole earth, and the Apollo space photographs. Annals of the Association of American Geographers, 84(2), 270-294. doi: 10.1111/j.1467-8306.1994.tb01738.x

D'Agnese, F. A. (2007). Utilizing internet-based community collaboration and 3D visualization tools to address issues of water resource sustainability. Abstracts of the 2007 Annual Meeting of the Geological Society of America. Denver, CO, 39(6), 13.

Del Casino, V. J., \& Hanna, S. P. (2000). Representations and identities in tourism map spaces. Progress in Human Geography, 24, 23-46. doi: 10.1191/030913200673388638

Dempsey, S. E., Parker, P. S., \& Krone, K. J. (2011). Navigating socio-spatial difference, constructing counter-space: Insights from transnational feminist praxis. Journal of International and Intercultural Communication, 4(3), 201-220. doi: 10.1080/17513057.2011.569973

Dickinson, G. (1997). Memories for sale: Nostalgia and the construction of identity in Old Pasadena. The Quarterly Journal of Speech, 83, 1-27.

Dicum, G. (2007, September/October). Eyes in the sky and on your desktop: With Google Earth, satellite images become an activist's ally. Sierra, 58-62.

Ewalt, J. P. (2011). The pain and exultation of representing place: Google Earth, environmental rhetoric, and the postmodern sublime. Aether: The Journal of Media Geography, 8(a), 25-41.

Ganesh, S., Zoller, H., \& Cheney, G. (2005). Transforming resistance, broadening our boundaries: Critical organizational communication meets globalization from below. Communication Monographs, 72, 169-191. doi: 10.1080/03637750500111872

Gang of villagers chase away Google car. (2009, April 3). Cable News Network Website. Retrieved January 5, 2010, from http://articles.cnn.com/2009-04-03/world

Graham, M. (2007, June 1). Introduction: The world is witness [Weblog Posting]. Retrieved January 25, 2010, from The World is Witness on Google Earth.

Graham, M. (2007, November 23). From a thousand hills [Weblog Posting]. Retrieved January 25, 2010, from The World is Witness on Google Earth.

Graham, M. (2007, November 24). Roadblocks [Weblog Posting]. Retrieved January 25, 2010, from The World is Witness on Google Earth.

Graham, M. (2007, November 25). Day becomes night [Weblog Posting]. Retrieved January 25, 2010, from The World is Witness on Google Earth.

Graham, M. (2007, November 27). The most beautiful hill in Rwanda [Weblog Posting]. Retrieved January 25, 2010, from The World is Witness on Google Earth.

Graham, M. (2007, November 28). Crisis in the Kivus [Weblog Posting]. Retrieved January 25, 2010, from The World is Witness on Google Earth

Graham, M. (2007, December 2). Goma on the Edge [Weblog Posting]. Retrieved January 25, 2010, from The World is Witness on Google Earth.

Graham, M. (2007, December 5). We sleep on stones [Weblog Posting]. Retrieved January 25, 2010, from The World is Witness on Google Earth.

Harris, C. (2007, May). Google Earth and the Omniscient Gaze. Unpublished paper presented at the 57th Annual Conference of the International Communication Association, San Francisco, CA.

Harvey, D. (1993). Class relations, social justice, and the politics of difference. In M. Pile \& S. Pile (Eds.), Place and the politics of identity (pp. 41-66). New York: Routledge. 
Hodgson, D., \& Schroeder, R. A. (2002). Dilemmas of counter-mapping community resources in Tanzania. Development and Change, 33(1), 79-100. doi: 10.1111/ 1467-7660.00241.

Jameson, F. (1991). Postmodernism: Or, the cultural logic of late capitalism. Durham, NC: Duke University Press.

Keith, M., \& Pile, S. (1993a). Introduction part 1: The politics of place. In M. Keith \& S. Pile (Eds.), Place and the politics of identity (pp. 1-21). New York: Routledge.

Keith, M., \& Pile, S. (1993b). Introduction part 2: The place of politics. In M. Keith \& S. Pile (Eds.), Place and the politics of identity (pp. 22-40). New York: Routledge.

Lagerkvist, A. (2008). Travels in thirdspace: Experiential suspense in mediaspace: The case of the America (un)known. European Journal of Communication, 23, 343-363. doi: $10.1177 / 0267323108092539$

Lefebrve, H. (1991). The social production of space (D. Nicholas-Smith, Trans.). Oxford, UK: Blackwell.

Lund, J. J., \& Macklin, S. (2007). ArcGIS and Google Earth: Rules of engagement. Paper presented at the 2007 ESRI Education Users Conference. San Diego, CA, 1-13.

Malone, M. (2007, March 12). WWF teams up with Google Earth [press release]. Retrieved January 5, 2010, from http://www.panda.org/ wwf_news $/$ ? uNewsID $=95920$

Martin, D. G. (2003). "Place-framing" as place-making: Constituting a neighborhood for organizing and activism. Annals of the Association of American Geographers, 93(3), 730-750. doi: 10.1111/1467-8306.9303011

Norton, T. (2009). Situating organizations in politics: A diachronic view of control-resistance dialectics. Management Communication Quarterly, 22, 525-554. doi: 10.1177/0893318908331099

Papa, M. J., Singhal, A., \& Papa, W. H. (2006). Organizing for social change: A dialectic journey of theory and practice. Thousand Oaks, CA: Sage.

Parks, L. (2009). Digging into Google Earth: An analysis of Crisis in Darfur. Geoforum, 40, 535-545.

Routledge, P., \& Cumbers, A. (2009). Global justice networks: Geographies of transnational solidarity. New York: Manchester University Press.

Sandberg, S. (2006). Fighting neo-liberalism with neo-liberal discourse: ATTAC Norway, Foucault, and collective action framing. Social Movement Studies, 5, 209-227. doi: 10.1080/14742830600991529

Shome, R., \& Hegde, R. S. (2002). Culture, communication, and the challenge of globalization. Critical Studies in Media Communication, 19, 172-189. doi: 10.1080/07393180216560

Slade, A. (2007). Lyotard, Beckett, Duras and the postmodern sublime. New York: Peter Lang.

Sletto, B. (2009). "Indigenous people don't have boundaries": Reborderings, fire management, and productions of authenticities in indigenous landscapes. Cultural Geographies, 16, 253-277. doi: 10.1177/1474474008101519

Stahl, R. (2010). Becoming bombs: 3D animated satellite imagery and the weaponization of the civic eye. Mediatropes, 2(2), 65-93. 
Stewart, J., \& Dickinson, G. (2008). Enunciating locality in the postmodern suburb: Flatiron crossing and the Colorado lifestyle. Western Journal of Communication, 72, 280-307. doi: 10.1080/10570310802210148

Tuan, Y. F. (1976). Space and place: The perspective of experience. Minneapolis, MN: University of Minnesota Press.

Tuan, Y. F. (1979). Space and place: Humanistic perspective. In S. Gale \& G. Olsson (eds.), Philosophy in geography (pp. 387-427). Ann Arbor: University of Michigan Press.

United States Holocaust Museum. (2009). Mapping initiatives: Be a witness. Retrieved March 10, 2010, from http://www.ushmm.org/maps

Wainwright, J., \& Bryan, J. (2009). Cartography, territory, property: Postcolonial reflections on indigenous counter-mapping in Nicaragua and Belize. Cultural Geographies, 16(2), 15-178. doi: 10.1177/1474474008101515

WITNESS. (2011). Witness: See it, film it, change it. Using video to open the eyes of the world to human rights violations. Retrieved May 15, 2011, from http:/ / www. witness.org/index.html

Wood, A. F. (2010). Two roads diverge: Route 66, "Route 66," and the mediation of American ruin. Critical Studies in Media Communication, 27(1), 67-83.

Zagacki, K., \& Gallagher, V. J. (2009). Rhetoric and materiality in the museum park at the North Carolina Museum of Art. Quarterly Journal of Speech, 95, 171-191. doi: $10.1080 / 00335630902842087$ 